Research Article

\title{
Flexural Toughness Properties of Reinforced Steel Fibre Incorporated Alkali Activated Slag Concrete
}

\author{
Srinivasan Karunanithi and Sivakumar Anandan \\ Structural Engineering Division, VIT University, Vellore 632014, India \\ Correspondence should be addressed to Sivakumar Anandan; sivakumara@vit.ac.in
}

Received 24 February 2014; Revised 20 June 2014; Accepted 15 July 2014; Published 24 July 2014

Academic Editor: Serji N. Amirkhanian

Copyright (C) 2014 S. Karunanithi and S. Anandan. This is an open access article distributed under the Creative Commons Attribution License, which permits unrestricted use, distribution, and reproduction in any medium, provided the original work is properly cited.

\begin{abstract}
The influence of steel fibre addition on the flexural properties of geopolymer based cementitious matrix was investigated in the present study. Slag based geopolymer mixtures were prepared with different binder and aggregate combinations. Strength gain and hardened properties of different geopolymer concrete mixtures were evaluated using accelerated curing techniques subjected to hot air oven and steam curing. Further, the steel fibre additions on the mechanical strength properties of a high strength geopolymer mixture were studied. A comprehensive evaluation on the post-crack toughness properties was assessed using four-point bend test. Test results exhibited that a geopolymer concrete of maximum compressive strength of $56.6 \mathrm{MPa}$ can be achieved with steam curing. Experimental observations also demonstrated that the steel fibre inclusions in geopolymer concrete provided adequate improvement on post-crack toughness properties and showed higher composite performance with increased volume fraction of steel fibres.
\end{abstract}

\section{Introduction}

Geopolymer based concrete received a wider acceptance among many researchers and can be a prospective application in future construction. The production of this material is cost effective and environment friendly as it is produced primarily from the industrial waste. The considerable research towards its potential use as a concreting material has led to the production of geopolymer concrete [1]. Synthesis of different geopolymer derivatives was found to be dependent on any silicate rich source material such as fly ash, furnace slag, bentonite, metakaolin, and rice husk ash. Like cement concrete, geopolymer based cementitious material is also a highly brittle material which exhibits poor tensile properties. This necessitates a comprehensive investigation to be conducted for improving the tensile properties of geopolymer concrete. Fibre addition in brittle cementitious matrix is a well-known technique to improve the toughness properties of the composite. Fibres are typically a discrete reinforcement mechanism used in either cement concrete or a geopolymer based concrete in order to provide adequate bending resistance [2]. The binder generally used in geopolymer concrete consisted of either slag or fly ash based system. Since fly ash and furnace slag is produced in large quantity as a waste from industry and needs to be disposed safely. This inevitably finds a potential alternative to be used as a construction material which can consume a large quantity [3]. Good toughening characteristics and crack resistance of geopolymer concrete can be achieved with the addition of discrete fibre leading to good matrix strengthening and reduced crack deflection properties. The matrix densification and fibre matrix interface can provide a higher load carrying capacity of geopolymer concrete depending upon the stiffness of the fibres. The steel fibres addition in geopolymer based cementitious composites provides post-crack ductility even upon repeated loading cycles [4]. Even though there exist several advantages of geopolymer based concrete, the poor toughness characteristic is the negative effect which restricts the wider applications. Different types of short fibre inclusions were also investigated in geopolymer concrete with slag based binder. The results demonstrated that the fibre addition provided adequate flexural strength enhancement 
TABLE 1: Properties of GGBFS used in the study.

\begin{tabular}{|c|c|c|c|c|c|c|c|c|c|c|c|c|c|c|}
\hline \multirow[b]{2}{*}{ Observation } & \multicolumn{4}{|c|}{ Physical properties } & \multicolumn{10}{|c|}{ Chemical composition (\%) } \\
\hline & Color & $\begin{array}{l}\% \text { passing } \\
\text { through } \\
45 \text {-micron } \\
\text { sieve (wet } \\
\text { sieving) }\end{array}$ & $\begin{array}{l}\text { Specific } \\
\text { gravity }\end{array}$ & $\begin{array}{l}\text { Blaine's } \\
\text { fineness } \\
\left(\mathrm{m}^{2} / \mathrm{kg}\right)\end{array}$ & $\mathrm{SiO}_{2}$ & $\mathrm{Al}_{2} \mathrm{O}_{3}$ & $\mathrm{Fe}_{2} \mathrm{O}_{3}$ & $\mathrm{CaO}$ & $\mathrm{MgO}$ & $\mathrm{SO}_{3}$ & $\mathrm{Na}_{2} \mathrm{O}$ & $\mathrm{K}_{2} \mathrm{O}$ & $\mathrm{Cl}^{-}$ & $\begin{array}{l}\text { Loss on } \\
\text { ignition }\end{array}$ \\
\hline Slag & White & 91.35 & 2.86 & 415 & 37.3 & 11.48 & 0.23 & 42.47 & 7.32 & 1.2 & - & - & - & - \\
\hline
\end{tabular}

and toughness to provide stability in the failure mode [57]. Limited studies investigated the reinforcing efficiency in geopolymer concrete and lack a systematic evaluation on its flexural performance. It is also understood from previous studies that the incorporation of fibres in geopolymer based concrete provided additional matrix strengthening leading to higher tensile performance provided with strain softening properties [8]. Compared to normal geopolymer concrete specimens fibre reinforced geopolymer concrete specimens are known to provide long term durability in terms of lower water absorption and chloride penetration. This could be anticipated due to the crack bridging properties of the fibres in geopolymer concrete as a result of fibres stretching the crack opening around the cracks [9].

Several studies reported that curing regime of geopolymer based concrete specimens requires a typical high temperature curing leading to faster geopolymer reactions and in this case of normal cured geopolymer specimens the activation energy can be provided with higher alkali concentration compared to lower level concentration [10]. It was reported that fibre addition had shown a reduction in strength gain in early ages; however upon subsequent hardening the matrix strengthening provided higher composite strength [11, 12]. Flexural strength gain in geopolymer concrete showed higher bending strength leading to higher toughness. In another study it was reported that incorporation of steel fibres provided good toughening mechanism with the increased volume fraction of steel fibres up to $0.7 \%$ [13-15]. Also, a reasonable increase in compressive, split tensile, and flexural properties was anticipated with the increase in volume fraction of steel fibres [16]. It is understood from the earlier studies that more appropriate method is required for characterizing the toughness properties of geopolymer concrete. In addition, the effects of activators on the strength enhancement and the rate of hardening properties under different high temperature curing need special attention.

1.1. Significance of the Present Study. The present study is aimed at investigating the post-crack improvements on the geopolymer based concrete with steel fibre inclusions. The engineering properties of the slag based geopolymer concrete with the effects of accelerated curing were systematically evaluated. Different slag based geopolymer concretes were prepared with various steel fibre dosages to investigate the mechanical properties of concrete. Toughness characterization and post-crack resistance properties of various geopolymer concretes was assessed from the load deformation characteristics. Test results from this study provide a reliable estimate on the prepeak and postpeak characteristics of various geopolymer concrete mixes.

\section{Materials Used and Testing Methodology}

2.1. Slag. Ground granulated blast furnace slag was used as a source material for geopolymer production and the various properties are given in Table 1.

2.2. Chemical Admixtures. Sodium hydroxide and sodium silicate based alkali activators were used for studying the geopolymerisation process. Different types of geopolymer mixes were prepared using sodium hydroxide at different concentration levels $(8 \mathrm{M}$ and $12 \mathrm{M})$ and sodium silicate to sodium hydroxide ratio of 1.5 . The improvement on consistency of concrete was achieved by adding an accelerator based superplasticizer (CERA-ACCL) at $1.5 \%$ by weight of slag. Initially, the alkali activator solution was prepared at desired molarity and kept in oven at $100^{\circ} \mathrm{C}$ for 4 hours prior to mixing in slag for faster initiation of geopolymer reaction. The different geopolymer concrete mixes evaluated in this study are given in Table 2. Initially, the calculated activator dosage is added to the slag and mixed in a Hobart mixer for two minutes. The accelerator based superplasticizer admixture was then added to improve the consistency and reaction efficiency of fresh geopolymer mixtures.

2.3. Fibre Reinforcements. Glued steel fibres of $35 \mathrm{~mm}$ length and $0.5 \mathrm{~mm}$ diameter with an aspect ratio of 70 were added in geopolymer concrete at various dosages of $0.5 \%, 1.0 \%$, and $1.5 \%$. The effects of steel fibre reinforcements were investigated in a high strength geopolymer mix (GC5) selected from compressive strength studies.

2.4. Curing Regime. An accelerated curing using hot air oven and steam curing was provided for the fresh geopolymer mixes. The specimens were cured in hot air oven curing (shown in Figure 1) at $100^{\circ} \mathrm{C}$ for 6 hours duration and a steam chamber (shown in Figure 2) at $75^{\circ} \mathrm{C}$ for 6 hours duration was used for curing the specimens. Later, the geopolymer specimens were remoulded and kept in ordinary room temperature $\left(37^{\circ} \mathrm{C} \pm 2^{\circ} \mathrm{C}\right)$ which was then tested at required curing period. 


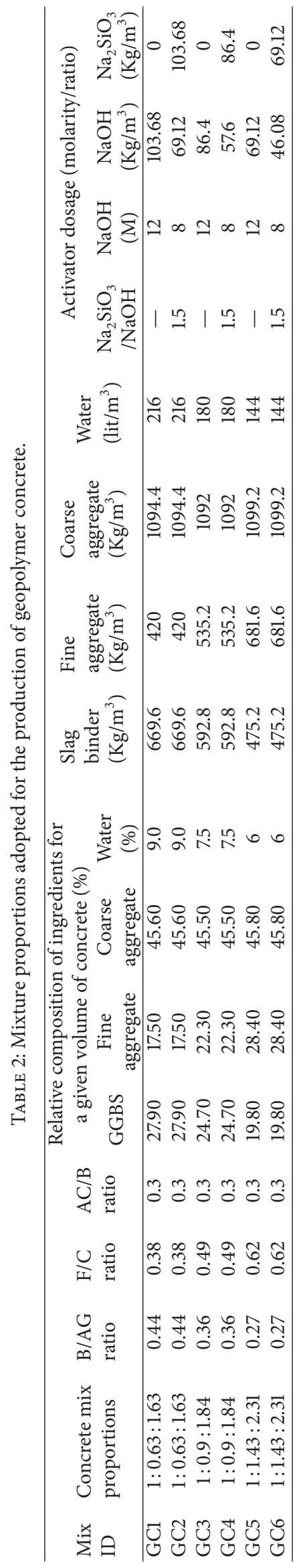




\subsection{Testing Methodology}

2.5.1. Compressive and Split Tensile Strength Test. Hardened geopolymer concrete specimens after required accelerated curing were tested for compressive strength, split tensile strength, and flexural strength. Compressive and split tensile strength of hardened geopolymer specimens were tested in a digital compression machine of $2000 \mathrm{KN}$ capacity operated at a loading rate of $2.5 \mathrm{KN} / \mathrm{sec}$. Cube specimens of size 100 $\times 100 \times 100 \mathrm{~mm}$ and cylindrical specimens of size $100 \times$ $200 \mathrm{~mm}$ and $150 \mathrm{~mm} \times 300 \mathrm{~mm}$ were used to assess the compressive, split tensile, and elastic modulus of various geopolymer concretes, respectively.

2.5.2. Flexural Strength Test. Flexural performance of various geopolymer concretes was evaluated using a concrete prism of size $100 \mathrm{~mm} \times 100 \mathrm{~mm} \times 500 \mathrm{~mm}$. The specimens were tested in a load controlled machine $(100 \mathrm{KN})$ at a loading rate of $2 \mathrm{kN} / \mathrm{sec}$ and subjected to third point loading arrangement (as shown in Figure 3). A Japanese yoke arrangement was used to measure the true deflection at the centre and the load deflection plots for various geopolymer concretes were drawn. From the test results, the various toughness measurements were calculated as given below.

(i) Absolute toughness was measured from the area under the entire load-deflection curve.

(ii) Postpeak toughness was calculated from the area between the ultimate load and failure load under the load-deflection curve.

(iii) Residual toughness was calculated from the area between the residual load (first drop in load after the peak load) and failure load under the load-deflection curve.

(iv) Toughness index $\left(\mathrm{Re}_{3}\right)$ is calculated from the ratio of average flexural strength after cracking till $3 \mathrm{~mm}$ deflection to that of ultimate flexural strength.

2.6. Concrete Mixture Proportioning. The constituents required for geopolymer concrete production arrived using particle packing models. In order to obtain an optimal requirement of binder content it was essential to derive the various constituents using particle packing. Packing models showed that the voids are primarily dependent on the interparticle spaces between the aggregates and that of finer particles. In the case of bulk volume occupied by coarse aggregate $(12 \mathrm{~mm})$ maximum void observed was around $0.0543 \mathrm{~m}^{3}$ and for fine aggregate it was around $0.0431 \mathrm{~m}^{3}$ (as seen in Figure 4). With the coarse aggregate being replaced with different percentage of fine aggregate a gradual increase in void percentage was noticed. However, when the packing of coarse aggregate and fine aggregate combination was optimum a maximum reduction in voids was observed. Theoretically this void (\%) was found to be equal to the binder content required for achieving a maximum strength. Also, the reduction in the coarse aggregate resulted in more volume of mortar required to close the voids. This also resulted in consumption of more binder volume to fill the

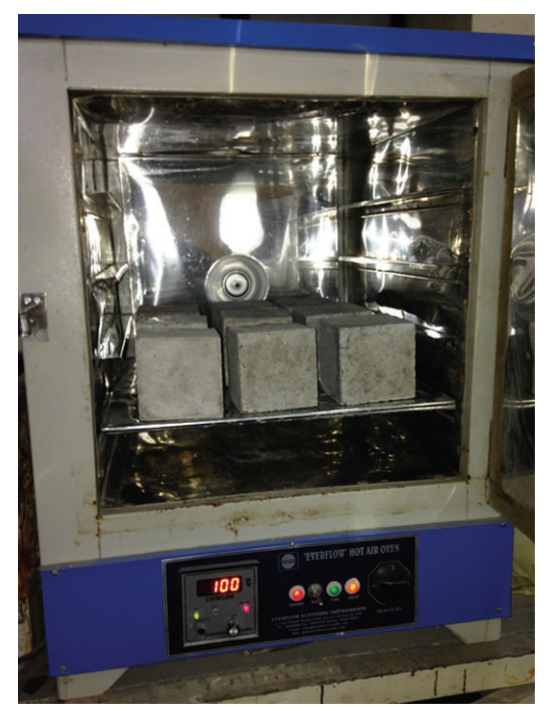

FIGURE 1: Geopolymer concrete specimens cured in hot air oven curing.

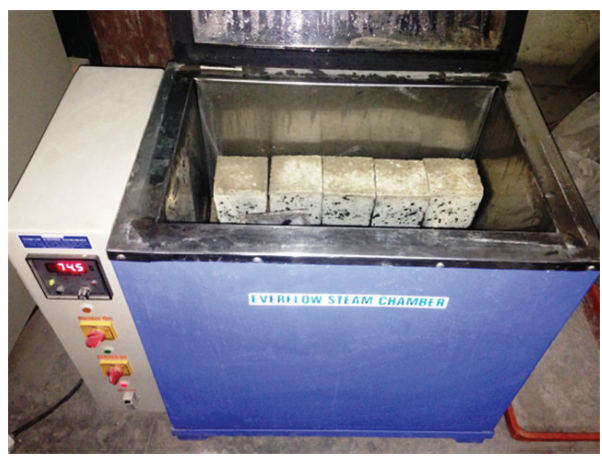

FIGURE 2: Geopolymer concrete specimens cured in steam chamber curing.

interparticle spaces between the finer materials. The different mortar to aggregate ratio was used to calculate maximum density of the concrete. In the case of two-phase material the maximum packing models with respect to coarse aggregate and mortar proportions were measured. It was observed that the maximum packing density was observed in the case of equal volume of aggregate to mortar replacement. Also, an apparent increase in the bulk density was noticed. Further, the final aggregate combinations of coarser fractions up to $25 \%$ and $75 \%$ finer aggregate fractions exhibited highest packing volume leading to maximum reduction in the voids. Based on the different packing models tested, the detailed aggregate proportions to that of binder content are provided in Table 2.

\section{Test Results and Discussions}

3.1. Hardening Process of Geopolymers. The initial hardening properties of geopolymer mixtures were appreciably influenced with the combined addition of alkali activators and accelerating admixture. Test results (as shown in Figure 5) indicated that the increase in concentration of alkali activator 


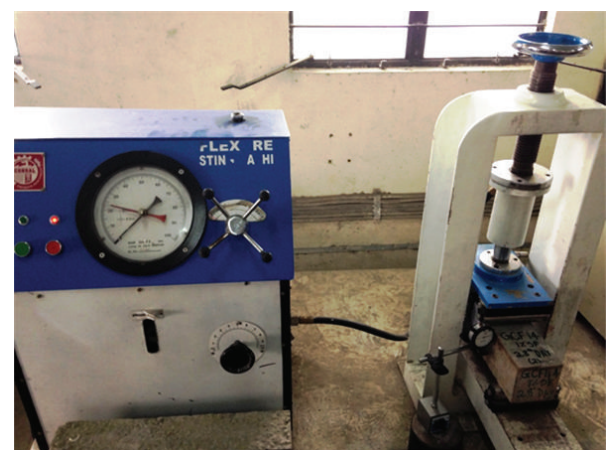

FIGURE 3: Third point loading arrangement in flexural strength testing machine.

resulted in the increase in rate of hardening of slag. Loss in consistency observed and further resulted in faster hardening within 15 to 20 minutes duration. This was anticipated for all fresh geopolymer mixtures at various concentration. It can be also noted that the rate of initial hardening was a function of concentration of alkali and the solution temperature at the time of mixing. The addition of sodium silicate to sodium hydroxide in the ratio of 1.5 showed a subsequent increase in the setting time properties. The initiation of polymerization occurred within few minutes after mixing alkali at higher concentration. Also, the initial high temperature mixing of alkali with the slag caused a subsequent increase in the reaction potential for the formation of alumino-silicate polymer chain. The combined effect on the addition of accelerator based superplasticizer and alkali activators was realized leading to increased reactivity of the geopolymer reaction between silica and alumina present in the slag, whereas accelerators possibly provided the instantaneous reaction occurring between the silicate and aluminates. This led to the continuous geopolymer chain reaction occurring for longer time duration without any retardation in hardening. This revealed that the addition of accelerator based superplasticizer stabilizes the rate of hardening properties in the case of geopolymer reactions which leads to the faster synthesis of alumino-silicate gel.

\subsection{Evaluation of Mechanical Properties}

3.2.1. Compressive Strength. The compressive strength values of various geopolymer mixes are provided in Table 3 and the graphical representation is provided in Figure 6. Test results clearly indicated that the compressive properties of geopolymer mixtures were primarily dependent on the packing density of constituent ingredients. Similarly, it was also observed that the compressive strength of steam cured geopolymer concretes exhibited a considerable improvement on the strength properties compared to oven curing. A maximum compressive strength of $56.6 \mathrm{MPa}$ was reported for steam chamber cured geopolymer concrete (GC5) and this was significantly higher than oven cured specimens. Most notably, the strength achievement was appreciable for concrete mixes containing a binder to aggregate ratio of 0.27 and fine to coarse aggregate ratio of 0.62 . The oven cured specimens for the same geopolymer mix (GC5) reported a maximum compressive strength up to $35.6 \mathrm{MPa}$. It is clearly noted that the effect of increase in binder content as well as the lower fine to coarse aggregate ratio does not result in the strength enhancement. The optimum selection of binder (19.80\%), fine aggregate $(28.40 \%)$, coarse aggregate $(45.8 \%)$, and activator solution (6\%) demonstrated an appreciable improvement on the compressive strength. The influence of steam curing was more pronounced in the case of geopolymer mixtures as it is known to provide accelerated rate of hardening. It can be noted that accelerated curing environment provides faster geopolymerisation process leading to rapid hardening within shorter curing period. The best geopolymer concrete (GC5) was further analyzed with the effect of steel fibre reinforcements at various dosages. The compressive strength results on the various steel fibre reinforced concretes are provided in Table 4 and the experimental trends are given in Figure 7 . Test results indicated that the increase in steel fibre dosage showed a reasonable improvement on the strength gain. However, the optimum steel fibre dosage up to $1.0 \% V_{f}$ showed a favorable strength increase up to $8 \%$ compared to unreinforced geopolymer mix (GC5) and reported a maximum compressive strength of $60.3 \mathrm{MPa}$. The steel fibre addition at $1.5 \% V_{f}$ did not result in any further increase of the compressive strength possibly due to reduction on the microstructural improvements.

Test results also demonstrated that all the geopolymer mixtures exhibited an early strength gain in 3 days and reported a marginal increase thereafter. This clearly indicates the early initiation of polymerization and the reaction saturates thereafter with a nominal strength gain upon further curing. In the case of all geopolymer mixtures, the 70 to $90 \%$ of the ultimate strength was achieved within 3 days of curing. This denoted that the geopolymerisation is a short term process that gains maximum strength within shorter time duration. The effects of steel fibre addition showed a reasonable increase on the compressive strength with optimum steel fibre volume fraction. It is well known from the fundamental fibre mechanics that the contribution of discrete fibres is not realized in compressive direction as failure is not due to ductile fracture. As a result, the stretching/straining of fibres is not experienced in compressive direction as a result, fibres does not contribute actively in load sharing. During the compression testing of plain high strength geopolymer concretes (GC5), no signs of bursting failure occurred. Whereas, in the case of steel fibre reinforced geopolymer concretes the failure occurred due to multiple cracking as a result of ductile failure mode. The careful examination on the fractured specimens revealed that discrete micro-cracking in the matrix zone as a result of the plastic deformation of polymer chain initiated the ductile failure.

3.2.2. Split Tensile and Elastic Modulus Properties. The split tensile and elastic modulus properties of best geopolymer mix (GC5) are provided in Table 4. A highest split tensile strength of $6.51 \mathrm{MPa}$ was recorded with the maximum steel fibre addition up to $1.5 \% V_{f}$. However, a maximum strength 


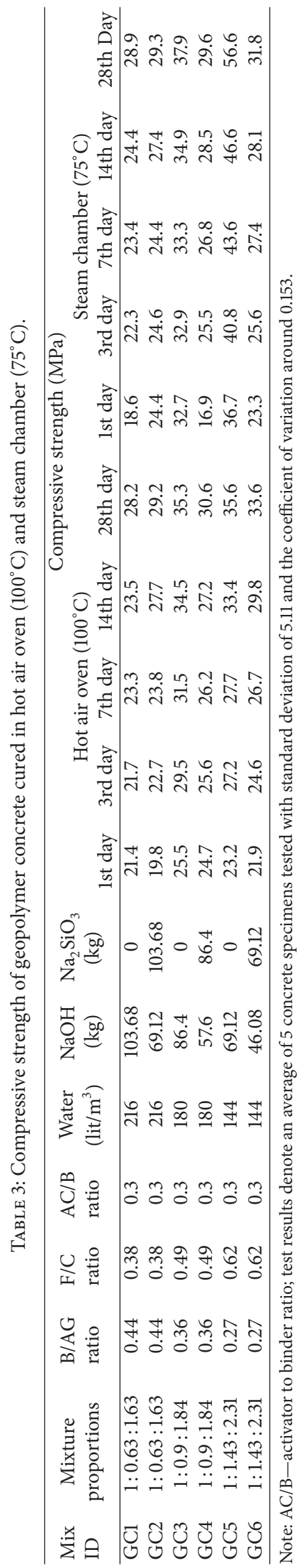




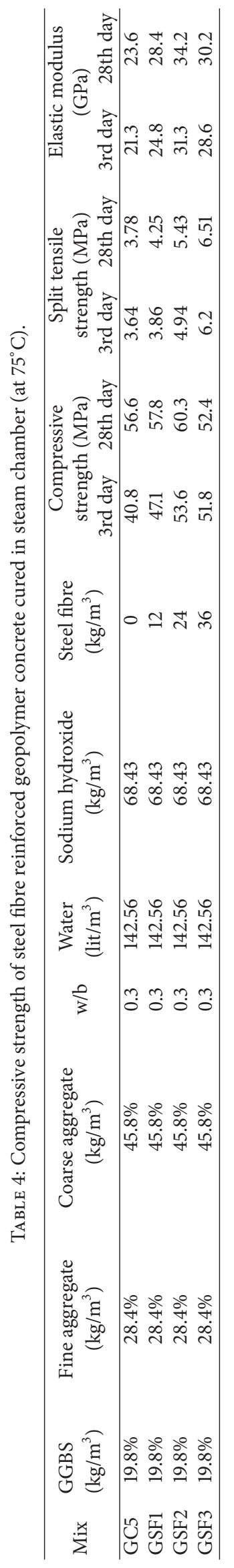




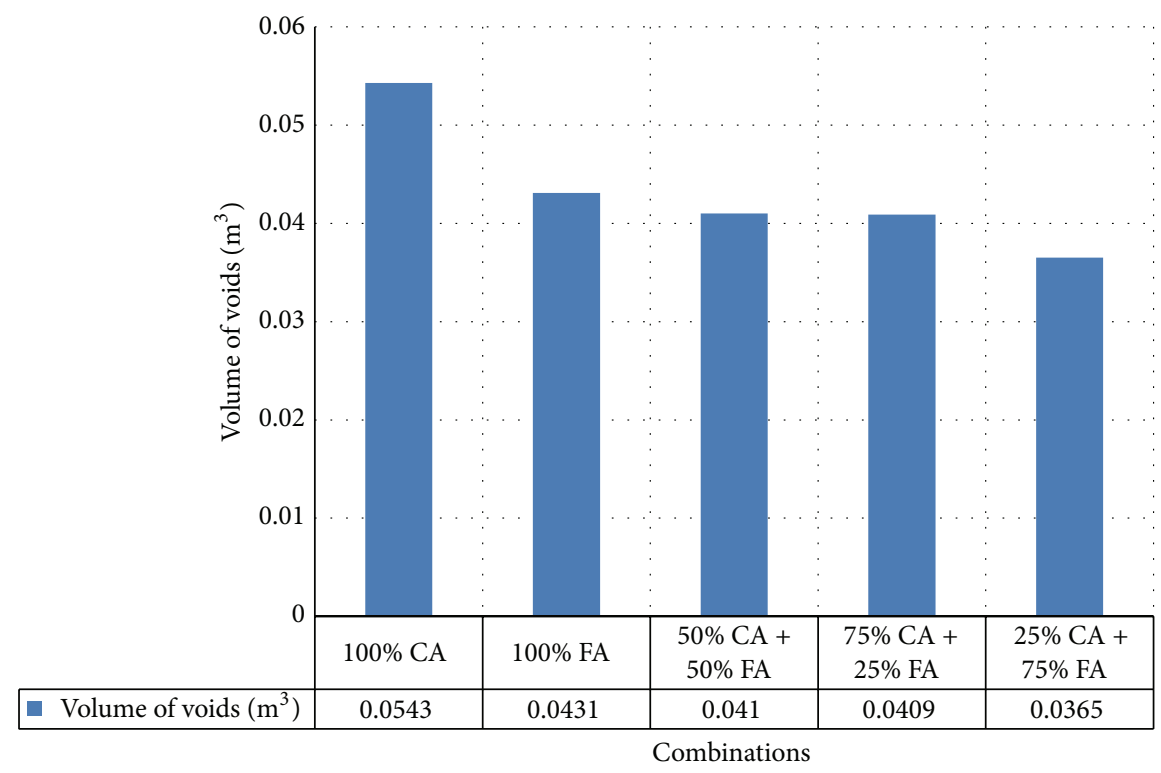

FIGURE 4: Volume of voids calculated from particle packing.

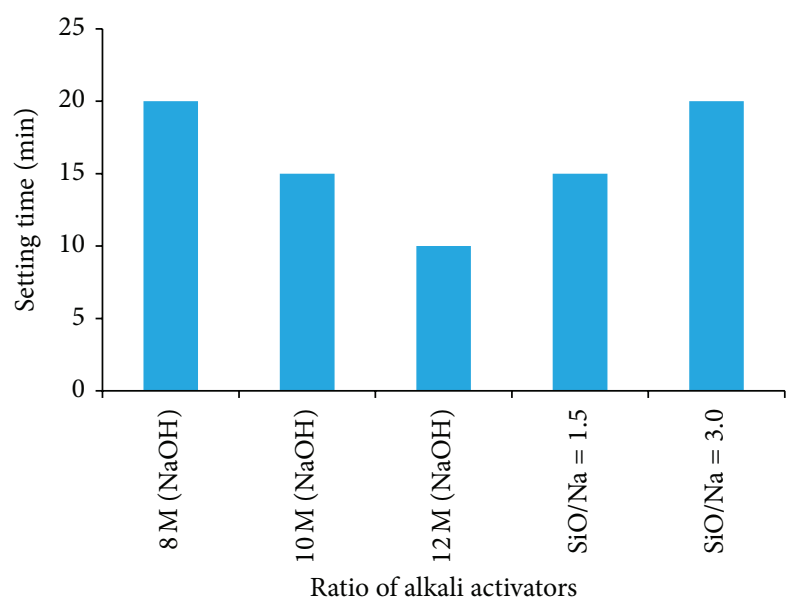

FIGURE 5: Setting time test for various dosages of alkali activators.

gain up to $85 \%$ of ultimate strength ( 28 days) was observed in 3 days for all geopolymer mixtures. Also, it can be seen from Figure 8 that the increased fibre dosage provided higher stress capacity in tensile direction. In addition an early strength gain was noticed within 3 days for all geopolymer concrete mixes. Unlike compressive stress, the split tensile properties were much influenced with the steel fibre addition in geopolymer concrete. Similarly, the elastic modulus of the geopolymer concretes with an increasing steel fibre content exhibited higher elastic modulus (as seen in Figure 9). This indicated that the geopolymer concretes containing discrete steel fibres showed better improvement in the matrix densification. This demonstrated appreciable deformation resistance of geopolymer concrete against compression leading to higher elastic modulus up to $34.2 \mathrm{GPa}$.
3.3. Flexural Bending Properties. The flexural bending properties of plain geopolymer concrete (GC5) and its performance with the inclusion of steel fibre reinforcement were further investigated. Bending resistance of various geopolymer concretes reinforced with steel fibres was assessed based on the flexural strength capacity and various toughness properties.

3.3.1. Flexural Strength. Flexural bending strength evaluated from the third point loading was used to calculate the flexural stress capacity. The summary of test results for various geopolymer concrete mixes is provided in Table 5. It can be noted that the flexural strength was found to be influenced with higher steel fibre addition as it recorded a favorable increase in the flexural strength. The experimental trends shown in Figure 10 represent clearly that the increased fibre dosage geopolymer concretes showed higher flexural strength. A maximum flexural strength of $13.2 \mathrm{MPa}$ was recorded in geopolymer concrete (GSF3) at higher steel fibre substitution up to $1.5 \% V_{f}$. This increase was higher than $46 \%$ more than plain geopolymer concrete mix (GC5) and revealed the fact that high fibre content in the matrix provided adequate bending resistance. It can be noted that compared to plain geopolymer the steel fibre substituted concrete mixes showed enhanced flexural strength. The steel fibres played a significant role during flexural bending as the proper distribution as well as random orientation of fibres provides high synergy to concrete. Ensures adequate matrix. The improvement on flexural stress capacity of geopolymer concrete specimens can be noted from the loaddeflection plot shown in Figure 11. It can be drawn from the experimental trends that the presence of steel fibres provided good prepeak strain hardening properties as well as postpeak softening properties. The increase in dosage of steel fibres 


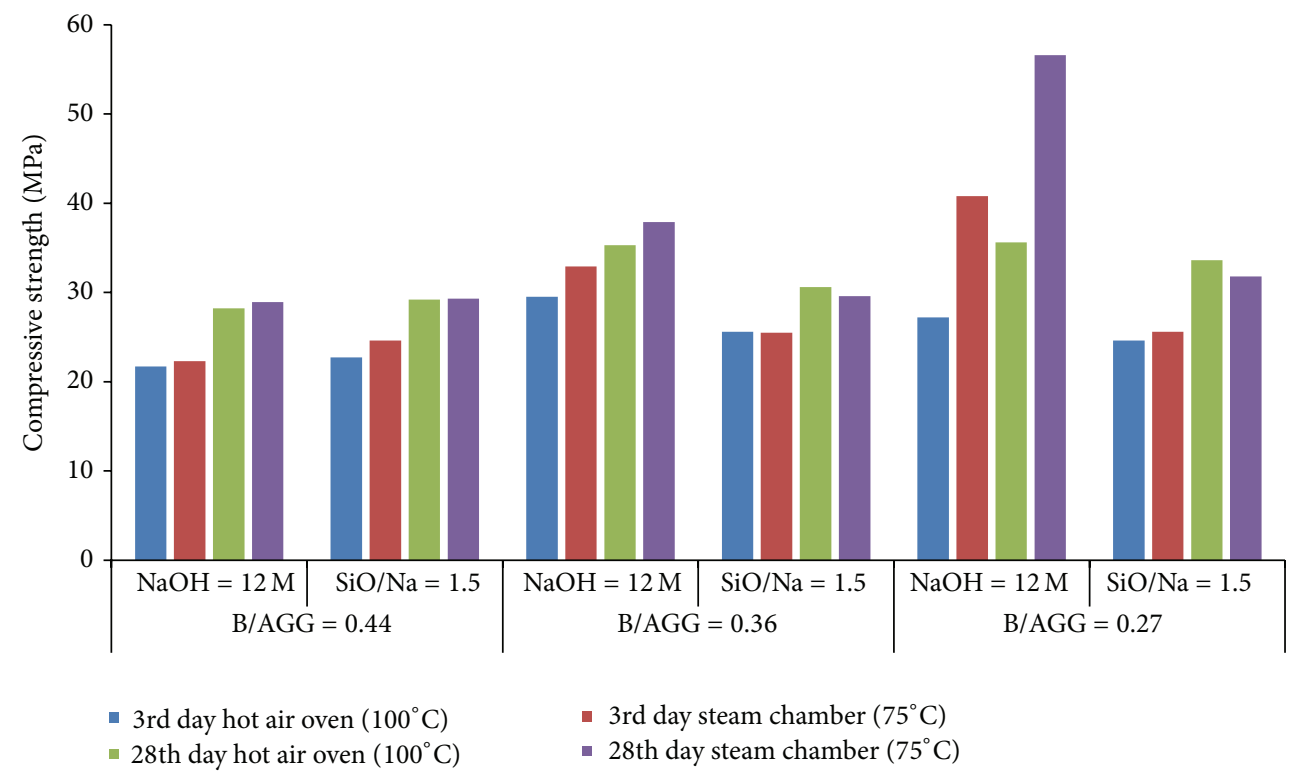

FIGURE 6: Compressive strength of various geopolymer concrete mixes tested.

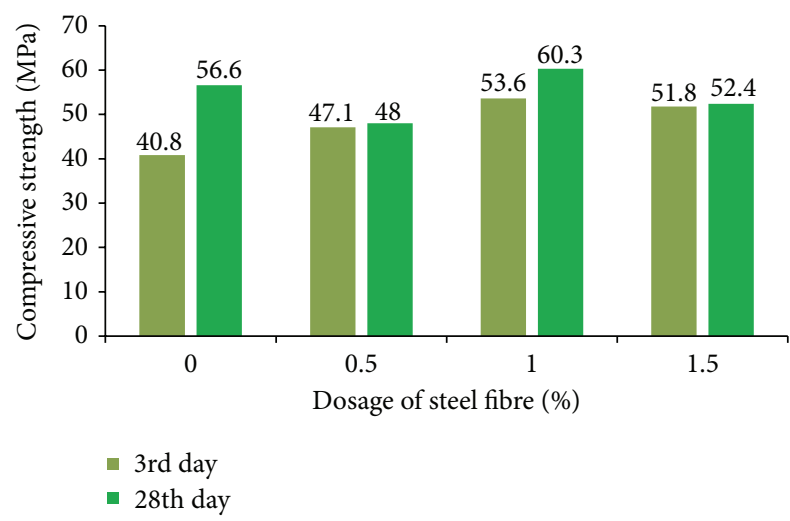

FIGURE 7: Compressive strength of various volume fractions of steel fibre reinforced geopolymer concrete mixes.

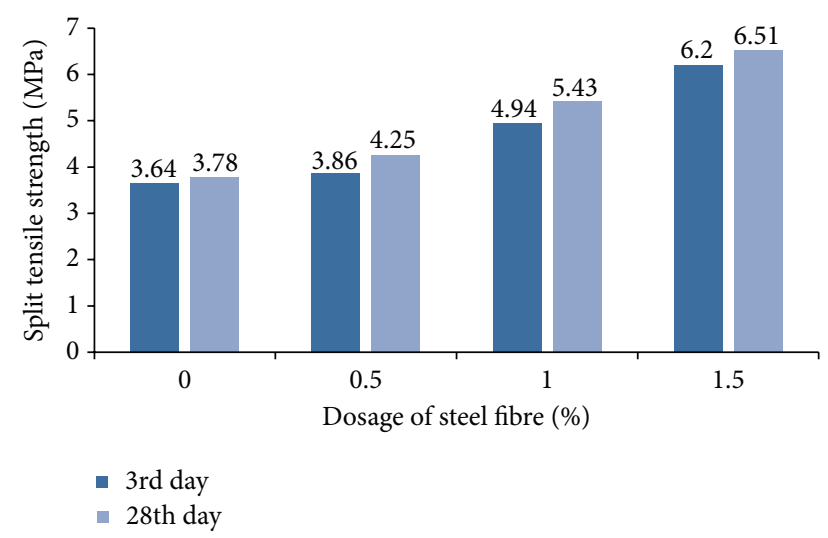

FigURE 8: Split tensile strength of various volume fractions of steel fibre reinforced geopolymer concrete mixes.

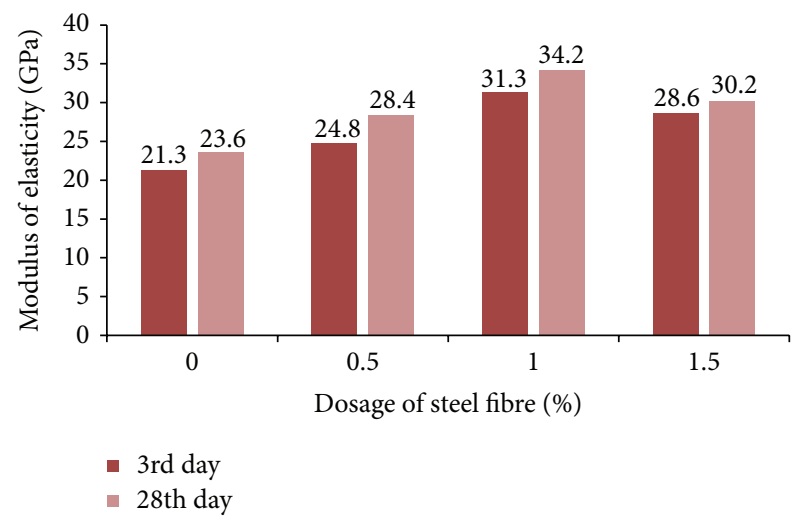

FIGURE 9: Modulus of elasticity for various volume fractions of steel fibre reinforced slag based geopolymer concrete cubes.

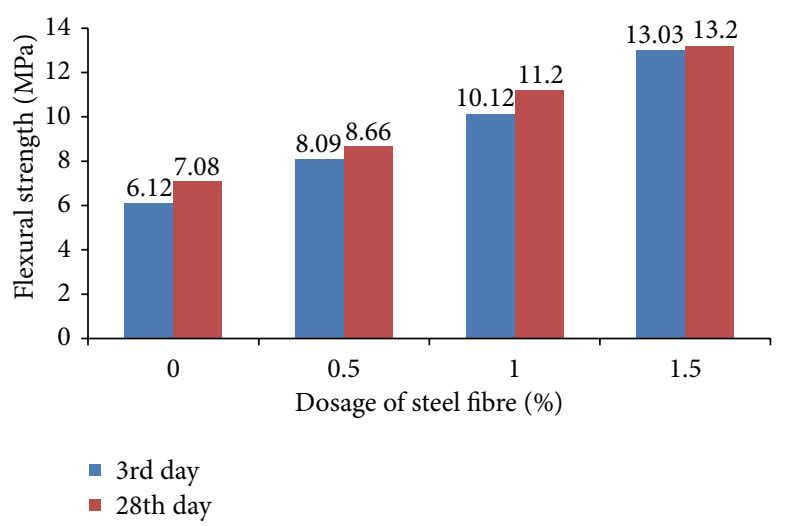

FIGURE 10: Flexural strength of various volume fractions of steel fibre reinforced geopolymer concrete mixes. 


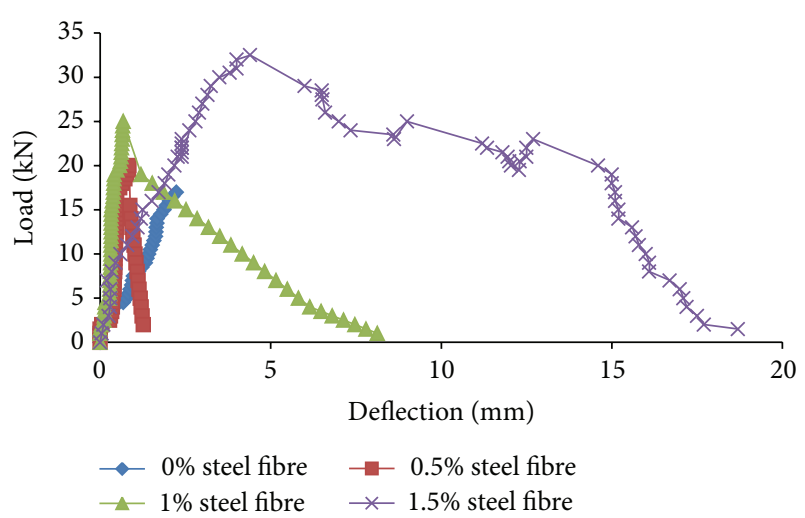

FIGURE 11: Load-deflection plots for various volume fraction of steel fibre reinforced geopolymer concretes at 28 days.

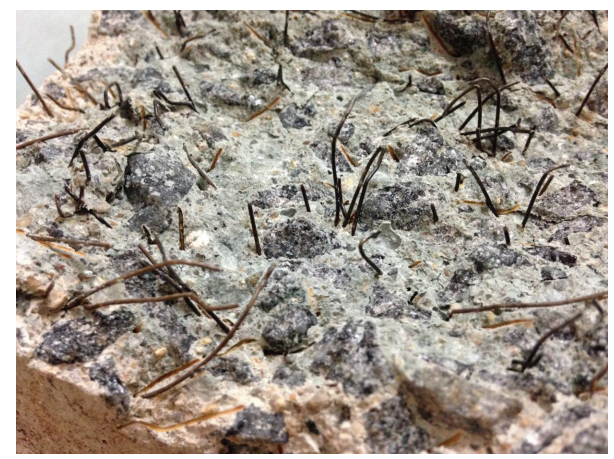

FIGURE 12: Fractured surface of geopolymer concrete showing fibre straining.

however had shown a good improvement on the post-crack resistance of concrete specimens.

3.3.2. Flexural Toughness. Flexural toughness was calculated from the load deflection plot of each concrete specimen and the absolute values are provided in Table 5. Toughness calculations from load deflection plots for various geopolymer concrete specimens were calculated using commercial software (Graph v 4.3). The real effects of steel fibre addition in geopolymer concrete are characterized by various toughness measurements determined as per the standard procedure. Test results indicated that the absolute and postcrack toughness was found to be increased with the increased steel fibre dosage. Similarly, the maximum attainment of the composite toughness was noticed well ahead of the early curing period (3 days). However, the further rate of hardening characteristics till 28 days air drying showed a marginal improvement on the ultimate strength capacity. The absolute toughness denoted the overall energy absorbed by the composite, whereas the post-crack toughness provides the strain softening properties of the composite due to selfstraining property of steel fibres during crack widening. Similarly, the other toughness measurements such as residual toughness and toughness index (Re3) were found to be higher for the geopolymer mix (GSF3) with high steel fibre content.
Toughness index of the composite was found to be dependent on the average stress capacity of steel fibres after cracking up to a maximum deflection of $3 \mathrm{~mm}$. Similarly it can be justified that the residual load of the steel fibre concrete depends on the load level after sudden drop in peak load. This mechanistic action of steel fibres was well received in all steel fibre substituted geopolymer concrete mixes providing high strain at failure. This improved the overall ductility of the composite due to stronger interfacial fibre matrix bond resulting in straining of steel fibres at the crack plane (as seen in Figure 12). It is understood that toughness of a composite material is an important measure representing the energy absorption capacity of hardened concrete and the energy released after failure. The larger presence of steel fibres across crack eventually undergoes large strain leading to high energy absorbing capacity. It is also evident from the results that high energy absorbing capacity is attributed due to large fibre availability near the crack front and high deformability of fibres during failure without fibre pullout. Also, it is understood from the test results that the fibre availability across the crack width is sufficient to transfer and redistribute the stress in the matrix. In general the evaluation of various toughness measurements indicated a reliable estimate on the dosage of steel fibres to be added in the geopolymer concrete to achieve a reliable performance index in terms of post-crack toughness properties.

\section{Conclusions}

Based on the above experimental studies the following salient conclusions are drawn.

(i) Slag based geopolymers were better synthesized in alkaline solution containing sodium hydroxide due to rapid polymerization and continuous chain reaction under accelerated curing techniques.

(ii) However, the rate of hardening was improved with the increase in the concentration of alkali, as well as the initial solution temperature $\left(100^{\circ} \mathrm{C}\right)$ during mixing with binder.

(iii) Accelerated curing techniques such as hot air oven curing and steam curing proved to be essential for early triggering of the polymerization and steam cured concrete specimens demonstrated the highest compressive strength of $56.6 \mathrm{MPa}$.

(iv) The slag activation with alkali solution containing sodium silicate and sodium hydroxide combinations does not exhibit pronounced effects on the strength gain as compared to that of sodium hydroxide activated slag mixes.

(v) All the geopolymer concretes tested showed an early strength attainment during the initial stages of curing period within 3 days. However, the long term curing effects (28 days) were not so phenomenal due to saturation of polymerization during the initial curing period itself.

(vi) The addition of alkali activator containing sodium hydroxide alone provided rapid geopolymerisation 
TABLE 5: Toughness properties of various steel fibre reinforced geopolymer concrete.

\begin{tabular}{|c|c|c|c|c|c|c|c|c|}
\hline \multirow{3}{*}{$\begin{array}{l}\text { Mix ID } \\
\text { Steel fibre dosage } \\
\text { Testing age (days) }\end{array}$} & \multicolumn{2}{|c|}{ GC5 } & \multicolumn{2}{|c|}{ GSF1 } & \multicolumn{2}{|c|}{ GSF2 } & \multicolumn{2}{|c|}{ GSF3 } \\
\hline & \multicolumn{2}{|c|}{$0 \%$} & \multicolumn{2}{|c|}{$0.50 \%$} & \multicolumn{2}{|c|}{$1 \%$} & \multicolumn{2}{|c|}{$1.50 \%$} \\
\hline & 3 & 28 & 3 & 28 & 3 & 28 & 3 & 28 \\
\hline Flexural strength $\left(\mathrm{N} / \mathrm{mm}^{2}\right)$ & 6.12 & 7.08 & 8.09 & 8.66 & 10.12 & 11.2 & 13.03 & 13.2 \\
\hline Absolute toughness (N-m) & 0.65 & 19.22 & 7.29 & 21.92 & 89.22 & 105.78 & 136.02 & 171.54 \\
\hline Post crack toughness $(\mathrm{N}-\mathrm{m})$ & 0 & 0 & 5.04 & 11.79 & 70.15 & 74.61 & 115.12 & 135.03 \\
\hline Residual toughness (N-m) & 0 & 0 & 4.13 & 10.83 & 63.37 & 30.31 & 103.57 & 157.43 \\
\hline Toughness index (Re3) & 0 & 0 & 0.38 & 0.42 & 0.41 & 0.45 & 0.54 & 0.76 \\
\hline
\end{tabular}

Note: test results denote an average of 3 concrete specimens tested with standard deviation of 12.25 and the coefficient of variation around 0.21 .

and the reaction potential was appreciable at higher concentration. Similarly, the initial mixing temperature of alkali solution provided a stable geopolymerisation for early hardening process.

(vii) Concrete proportions that arrived using packing models showed ideal combinations of binder to aggregate proportions and exhibited good compressive strength properties for various geopolymer mixes. Most notably, the higher fine to coarse aggregate ratio of 0.62 and lower binder to aggregate ratio of 0.27 exhibited maximum compressive strength properties of the composite.

(viii) Steam cured geopolymer concrete mixes exhibited the highest compressive strength of $56.6 \mathrm{MPa}$ and this was found to be higher than oven cured concrete mixes. A similar improvement on the other mechanical properties (split tensile and elastic modulus) was anticipated for accelerated steam cured concretes.

(ix) Steel fibre inclusions in geopolymer mix showed a marginal increase $(8 \%)$ on the compressive strength properties; however this improvement was anticipated only at optimal steel fibre dosage of $1.0 \% V_{f}$.

(x) Flexural bending properties of the geopolymer composite were found to be higher with increasing steel fibre dosage and exhibited improved strain hardening properties of the hardened concrete as observed from the load-deflection characteristics.

(xi) Test results demonstrated that the geopolymer composite attains the maximum toughness at early ages of accelerated curing and any further curing showed only marginal improvements on the hardening characteristics.

(xii) It is also understood that various toughness measurements showed the relative performance of steel fibre dosage on the crack bridging properties leading to higher strain softening properties of the composite.

(xiii) Post-crack toughness properties of geopolymer concrete were found to be dependent on the maximum fibre availability leading to high strain at failure.

(xiv) Toughness measurements provide a reliable estimate on the fibre performance in geopolymer concrete and suggest the dosage of steel fibres required for desired levels of composite performance.

\section{Conflict of Interests}

The authors declare that there is no conflict of interests regarding the publication of this paper.

\section{References}

[1] J. Davidovits, "Geopolymers and geopolymeric materials," Journal of Thermal Analysis, vol. 35, no. 2, pp. 429-441, 1989.

[2] D. S. de Toledo Pereira, F. J. da Silva, and C. Thaumaturgo, "High-performance fiber reinforced geopolymer concrete for pavement," in Proceedings of the 2nd international Airports Conference: Planning, Infrastructure \& Environment, São Paulo, Brazil, 2006.

[3] H. Gokulram and R. Anuradha, "Strength studies on polypropylene fibre reinforced geopolymer concrete using M-sand," Journal of Emerging Trends in Engineering and Development, vol. 2, no. 3, pp. 242-250, 2013.

[4] R. Vijai K, R. Kumutha, and G. B. Vishnuram, "Effect of inclusion of steel fibres on the properties of geopolymer concrete composites," Asian Journal of Civil engineering (Building and Housing), vol. 13, no. 3, pp. 377-385, 2012.

[5] T. S. Ng, N. S. T. Htut, and J. S. Foster, "Mode I and II fracture behaviour of steel fibre reinforced high strength geopolymer concrete: an experimental investigation," in Fracture Mechanics of Concrete and Concrete Structures, pp. 1504-1511, Korea Concrete Institute, 2010.

[6] S. Deepa Raj, A. Ruby, N. Ganesan, and S. Divya, "Fracture properties of fibre reinforced geopolymer concrete," Journal of Scientific \& Engineering Research, vol. 4, no. 5, pp. 75-80, 2013.

[7] A. Natali, S. Manzi, and C. M. Bignozzi, "Novel fiber-reinforced composite materials based on sustainable geopolymer matrix," Procedia Engineering, vol. 21, pp. 1124-1131, 2011.

[8] P. K. Sarker, R. Haque, and K. V. Ramgolam, "Fracture behaviour of heat cured fly ash based geopolymer concrete," Materials and Design, vol. 44, pp. 580-586, 2013.

[9] F. U. A. Shaikh, "Review of mechanical properties of short fibre reinforced geopolymer composites," Construction and Building Materials, vol. 43, pp. 37-49, 2013.

[10] R. D. Moser, P. G. Allison, B. A. Williams et al., "Improvement in the geopolymer-to-steel bond using a reactive vitreous enamel coating," Construction and Building Materials, vol. 49, pp. 6269, 2013.

[11] F. U. A. Shaikh, "Deflection hardening behaviour of short fibre reinforced fly ash based geopolymer composites," Materials and Design, vol. 50, pp. 674-682, 2013. 
[12] A. R. Sakulich, "Reinforced geopolymer composites for enhanced material greenness and durability," Sustainable Cities and Society, vol. 1, no. 4, pp. 195-210, 2011.

[13] S. Bernal, R. de Gutierrez, S. Delvasto, and E. Rodriguez, "Performance of geopolymeric concrete reinforced with Steel fibers," in Proceedings of the 10th International Inorganic-Bonded Fiber Composites Conference (IIBCC '06), pp. 156-167, Universidade de Sao Paulo, University of Idaho, Sao Paulo, Brazil.

[14] S. Bernal, R. de Gutierrez, S. Delvasto, and E. Rodriguez, "Performance of an alkali-activated slag concrete reinforced with steel fibers," Construction and Building Materials, vol. 24, no. 2, pp. 208-214, 2010.

[15] S. A. Bernal, J. Bejarano, C. Garzón, R. M. De Gutiérrez, S. Delvasto, and E. D. Rodríguez, "Performance of refractory aluminosilicate particle/fiber-reinforced geopolymer composites," Composites B, vol. 43, no. 4, pp. 1919-1928, 2012.

[16] Z. Yunsheng, S. Wei, L. Zongjin, Z. Xiangming, Eddie, and C. Chungkong, "Impact properties of geopolymer based extrudates incorporated with fly ash and PVA short fiber," Construction and Building Materials, vol. 22, no. 3, pp. 370-383, 2008. 

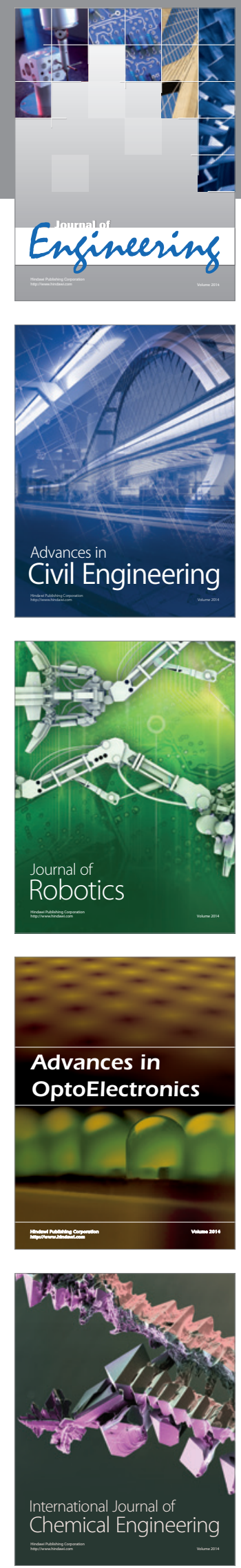

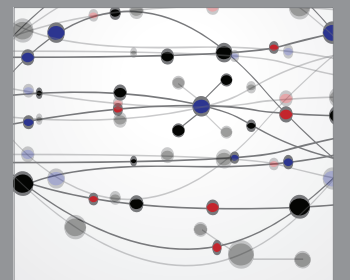

The Scientific World Journal
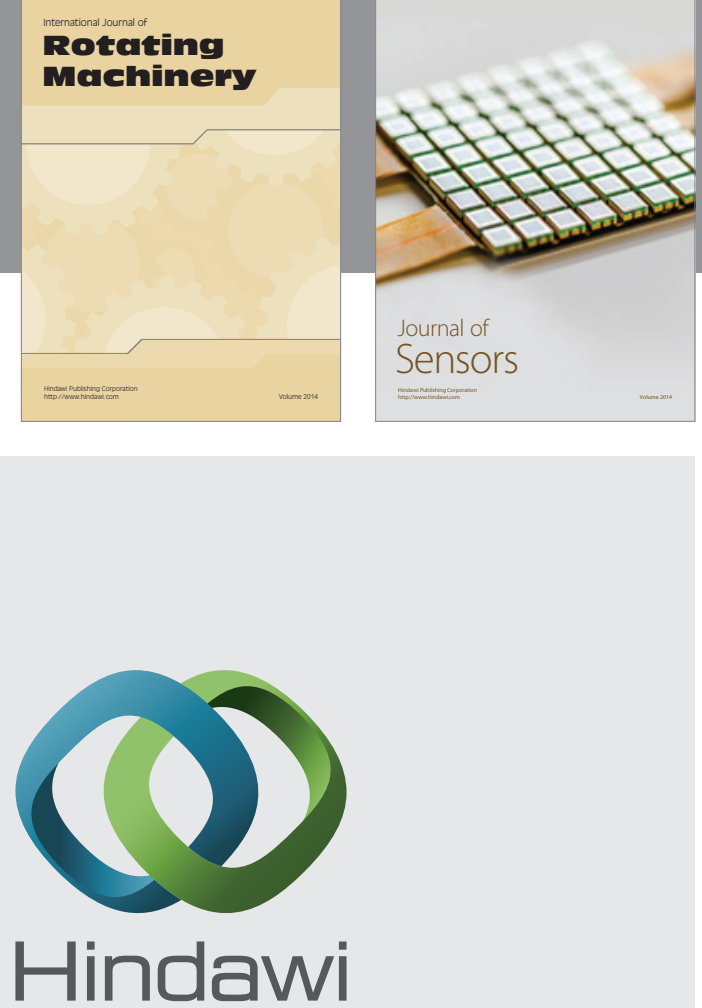

Submit your manuscripts at http://www.hindawi.com
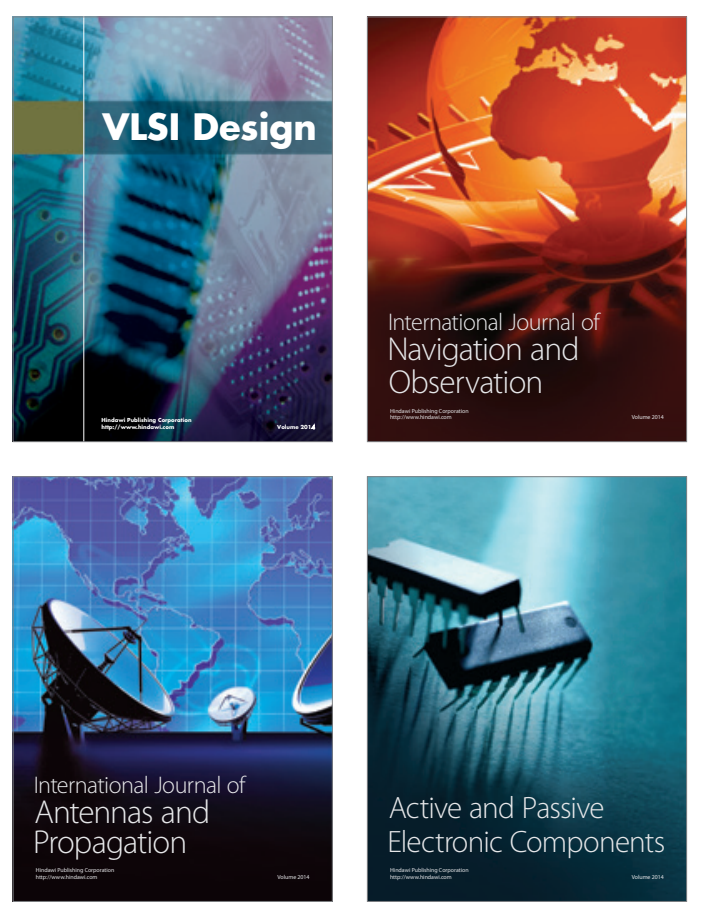
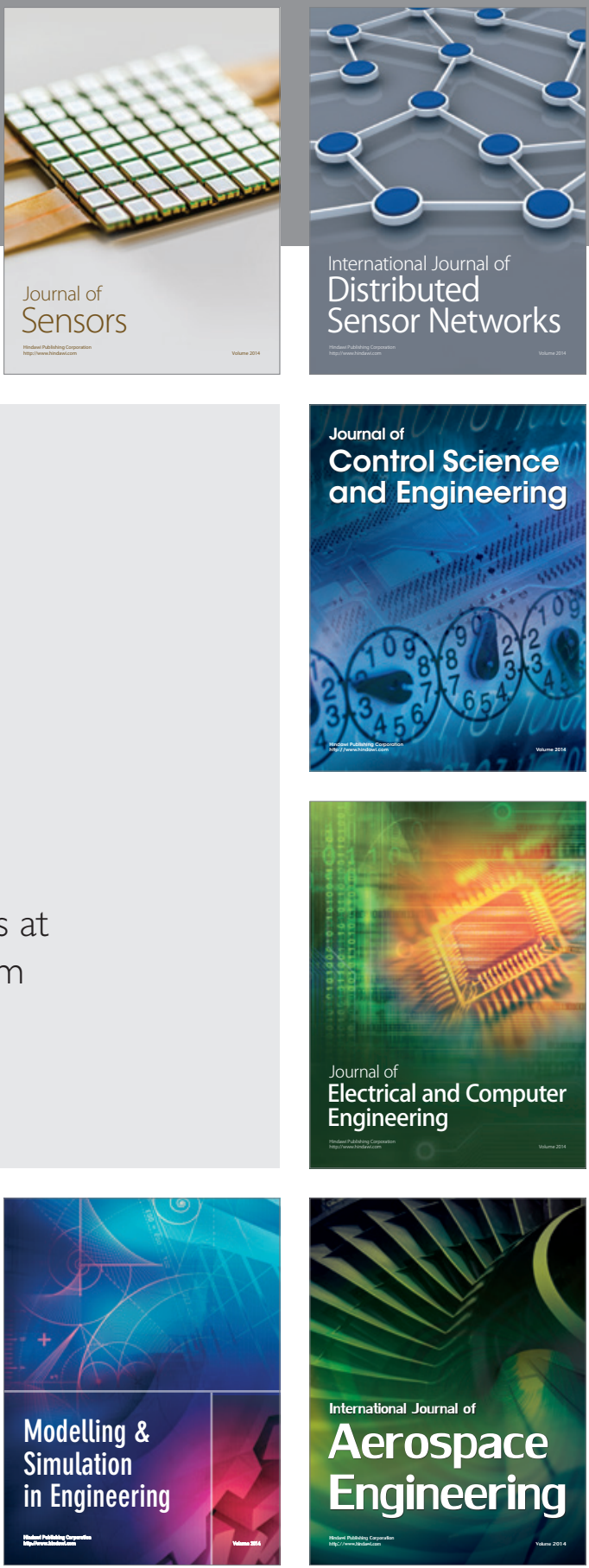

Journal of

Control Science

and Engineering
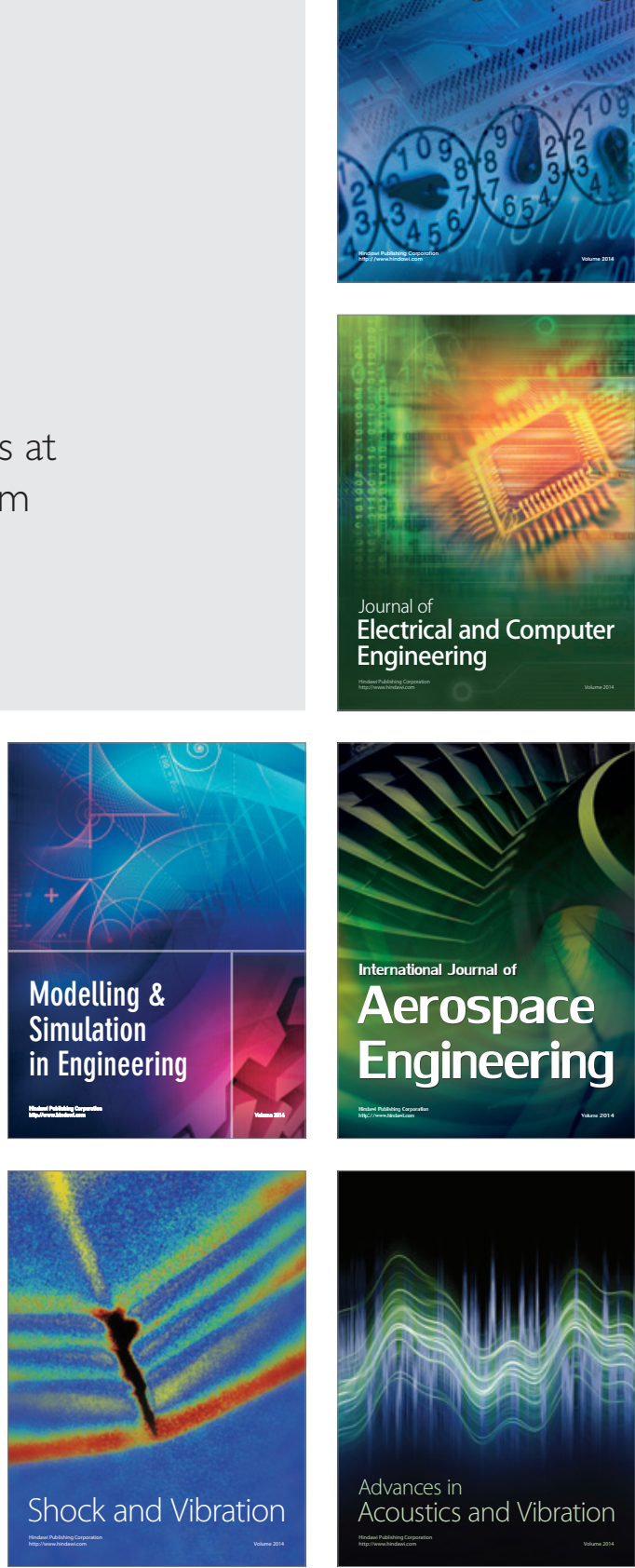